University of Nebraska - Lincoln

DigitalCommons@University of Nebraska - Lincoln

Faculty Publications, Department of Child, Youth, and Family Studies

Child, Youth, and Family Studies, Department of

2020

Ethics Based Training for Clinicians: Moving Beyond Ethical

Decision Making Models

Bobbi J. Miller

Paul R. Springer

Follow this and additional works at: https://digitalcommons.unl.edu/famconfacpub

Part of the Developmental Psychology Commons, Family, Life Course, and Society Commons, Other Psychology Commons, and the Other Sociology Commons

This Article is brought to you for free and open access by the Child, Youth, and Family Studies, Department of at DigitalCommons@University of Nebraska - Lincoln. It has been accepted for inclusion in Faculty Publications, Department of Child, Youth, and Family Studies by an authorized administrator of DigitalCommons@University of Nebraska - Lincoln. 


\title{
Ethics-Based Training for Clinicians: Moving Beyond Ethical Decision Making Models
}

\author{
Bobbi J. Miller ${ }^{1}$ and Paul Springer ${ }^{2}$
}

1 Department of Couple and Family Therapy, Regis University, 500 East 84th Avenue, Suite B-12, Thornton, C0 80229, USA

2 Department of Child, Youth, and Family Studies, University of Nebraska-Lincoln, 138 Mabel Lee Hall, Lincoln, NE 68588, USA

Corresponding author — Paul Springer pspringer3@unl.edu

\begin{abstract}
Clinical training in ethical decision making processes has relied heavily on teaching students to apply ethical codes and legal statutes to written scenarios using ethical decision making models. While an excellent academic exercise, this approach tends to remain abstract and does not prepare students for the complexities of making decisions during the process of therapy. Recently, experts in the field have called for reforms in ethical training, believing current models must move beyond cognitive exercises that detach students from the humanity of their clients and themselves. The described pedagogical approach bridges the gap by using a modified Objective Structured Clinical Exam to provide a safe context for students to practice ethical decision making and receive feedback before entering actual clinical practice.
\end{abstract}

Keywords: Ethics, Training, Decision making models, Experiential activities, Objective structured clinical evaluation (OSCE)

Published in Contemporary Family Therapy 42 (2020), pp 370-380

DOI:10.1007/s10591-020-09537-7

Copyright () 2020 Springer Science+Business Media, LLC. Used by permission. 
"There is nothing more useless than a merely well informed [person]"

- Alfred North Whitehead.

Beginning-level clinicians, regardless of discipline, confront a myriad of ethical dilemmas as they endeavor to provide effective and competent treatment. These ethical dilemmas have become an issue of growing concern and reflect an awareness that resources for decision making in these situations may be limited (Caldwell and Stone 2016; Levitt et al. 2015; Green and Hansen 1989; McLaurin and Ricci 2003; McLaurin et al. 2004; Woody 1990). Beginning level clinicians need to be better prepared to enter the wider social and cultural workforce, while working within their relevant professional codes and state laws. In fact, positive ethical decision making requires not only a commitment to ethical ideals and standards, but access to necessary tools and skills that can be utilized when faced with challenging and compelling ethical dilemmas. As educators with over 30 years of combined experience training therapists, we have noted that new therapists have little practice in addressing these ethical issues, outside of academic activities within ethics focused courses, prior to being confronted with dilemmas that involve actual clients.

Within the United States, the predominant existing approach to providing this foundational educational experience regarding addressing ethical dilemmas has been to focus on exercises applying ethical decision-making models to case scenarios. This approach has become a mainstay in ethics and legal training within most clinical training programs. In fact, in the last three decades more than 30 discrete ethical decision-making models have been introduced in the ethics literature (Cottone and Claus 2000). These varied models of ethical decision making cover a variety of foci (Corey et al. 2014; Forester-Miller and Davis 1996; Hicks and Cornile 1999; Kitchener 1984; Koocher and Keith-Spiegel 2008; Levitt et al. 2015; Tarvydas et al. 2015) to support clinicians, in all stages of development, to deal with the complexity involved in addressing situations as they arise in clinical practice. These have largely been cognitive, rational-evaluative models that rely on critical thinking (Murphy and Hecker 2016) and focus on an individual's understanding and written or oral application of professional ethical codes and legal statutes. Some of these models are empirical, while others are derived 
from practice or anecdotal evidence (Cottone et al. 2007). A common feature of all is that they slow down the decision-making process and allow clinicians to consider situations from multiple perspectives.

Ethical dilemmas are rarely straightforward and clinicians may find themselves overwhelmed with the sheer volume of clinical information and contingencies that need to be considered in determining how to proceed (Levitt et al. 2015). One of the benefits of ethical decisionmaking models, especially for beginning level therapists, is they provide a way to organize and prioritize information so the clinician is able to proceed in a time sensitive manner without sacrificing the attention to detail that is important in coming to a sound ethical and clinical decision (Cottone and Claus 2000; Wilcoxon et al. 2012). For student therapists, these models also offer opportunities to gain practice in generating sophisticated solutions. This is accomplished by following a series of steps that require justification, as opposed to making a truncated decision without truly considering the benefits and consequences of one's decision (Murphy and Hecker 2016). While these exercises are useful, they tend to remain abstract and offer little further guidance for determining the best course of action among several choices that meet the minimal bar of professional acceptability (Caldwell and Stone 2016). They also do little to help facilitate a student's connection with the human aspects of ethical decision making in clinical work and as a result, their application to practice is limited at best (Levitt et al. 2015). For example, McLaurin et al. (2004) argue that even as beginning therapists' skills grow, so does their ability to rationalize theoretical positions and decision-making practices (Todd and Storm 1997). This ability to rationalize behaviors both lead them to justifying their epistemological stance and also makes it easier to ignore basic ethical guidelines in an attempt to do what is in the best interest of their client (McLaurin et al. 2003). Because of this, it is not clear how these models prepare clinicians to know how to deal with ethical violations because as clinicians gain more experiences, they are increasingly likely to rationalize their decision making, even when said violations have occurred (Coy et al. 2016). This is further supported by Jankowski and Martin (2003), who examined the decision-making process of family therapists as they determined whether to report cases of child-maltreatment. In this study the authors found large variability in responses across therapists. This variability was consistent regardless 
of whether the therapist chose to report or not and across different types of abuse and neglect (e.g., emotional, physical, and sexual). The variability seemed to reveal that despite the number of decision-making models available and the focus on their implementation in training, these models do not seem to prepare clinicians for how to make determinations on complex ethical quandaries such as whether to report child maltreatment. Instead, trainees could benefit from more practical resources when it comes to ethical decision-making.

In his 2008 AAMFT plenary address, entitled "Being good, doing good: The virtue of goodness in ethical practice" Frank Thomas, Ph.D. challenged the field to go beyond using written case scenarios in training clinical students. He believed clinicians in training must understand the complexities of ethical decision making beyond the cognitive exercises; which include emotional, intuitive, and relational aspects of making these determinations. Thomas argued that a focus on written scenarios runs the risk of detaching students from their client's humanity or personhood, which is paramount in the virtue of goodness in ethical practice (2008).

This coincides with the call within the psychotherapy field for a focus on positive ethics, which shifts the focus from misconduct and disciplinary consequences to higher ethical aspirations, consistent with virtue ethics (Bush et al. 2006; Handelsman et al. 2002). Virtue ethics is the idea that the role and character of the individual engaged in making the decision is equally as important as doing one's duty or acting in order to bring about good. In fact, core values in virtue ethics are focused on attending to the humanity of clients by fostering autonomy, protecting clients from harm, taking steps to assure therapy is beneficial, being honest with clients, keeping promises, and promoting justice (Corey et al. 2014: Wilcoxon et al. 2012; Melito 2003; Cottone and Claus 2000; Murphy and Hecker 2016). It has also been argued that models of ethical decision making should solicit client involvement (i.e., participatory decision making) in the decision-making process to produce the best possible outcomes (Tarvydas et al. 2015). Regardless of the approach, this element of attending to a client's humanity can be considered core to clinical and ethical competence. 


\section{Clinical and Ethical Competence}

One of the challenges in clinical programs is training students and assessing competence in a robust and developmentally appropriate manner, particularly regarding ethical practice. Traditionally, clinical programs have addressed the issue of ethical competence in two ways. First, they have focused on tests of cognition, or academic exercises that demonstrate how well trainees can recite the knowledge gained from courses. While content knowledge is important and necessary in developing competent clinicians, it falls short in developing clinicians who are adept in showing how they apply what they know of ethics into practice. This notion of self-reflexivity, which is essential for the development of competent beginning level therapists, is at risk of not being nurtured and grown within this training model. In fact, there seems to be little evidence that how a student performs in an academic knowledge-based setting can accurately predict what a graduate does when functioning in clinical practice (Miller 1990) especially in specific to ethical decision making (Foster and Black 2007; Levitt et al. 2015). For example, while students may acquire an academic knowledge of ethical dilemmas and decision making they may simultaneously struggle to grasp the complexities of the situations described, the influence of their personal beliefs and biases, and the impact of decisions made on the clients involved.

The second approach training programs utilize to evaluate student ethical competencies is live or case supervision training models. The literature examining the impact of supervision primarily focuses on monitoring the professional development of the therapist, their socialization into the profession and protecting the well-being of clients (Inman et al. 2014; Mead 1990; Milne 2014; Morgan and Sprenkle 2007; Taylor and Gonzales 2005; Todd and Storm 1997). However, a closer look at these articles highlights that more attention is given to theoretical and professional development of students than preparing and training students to competently address ethical dilemmas. As a result, a less proactive approach to ethics may be taken where supervisors instead address ethical issues in a reactionary way, often after an ethical dilemma has arisen. This is a serious limitation in training models (Levitt et al. 2015), and one that was addressed by Miller specific to the larger context of clinical 
training $(1990 ; 2010)$. He argued clinicians must be able to demonstrate the application of their knowledge into practice before they encounter actual clients or they are nothing more than a "well-informed" person (Miller 1990, p. 563).

\section{Simulation-Based Learning, OSCE's and Ethics}

As a means to address these challenges, simulation-based learning activities such as the Objective Structured Clinical Examination (OSCE) have been developed and applied across many different disciplines and trainees (Lateef 2010). This technique is used to "amplify real experiences with guided ones, often immersive in nature that evoke or replicate substantial aspects of the real work in a fully interactive fashion" (Lateef 2010, p. 348). This technique provides a platform for professionals in training to practice their knowledge and skills of clinical decision making while mitigating ethical tensions and resolving practical dilemmas (Lateef 2010). In fact, medical programs have developed simulation-based learning activities as a means to not only evaluate students but to protect patient safety by allowing students to practice skills in the safety of the class setting (Edinger et al. 1999). OSCEs involve using simulated clinical situations as a tool in both training and conducting evaluations of trainee's competence. OSCEs are more efficient and effective than other testing methods at assessing skills in communication, managing relationships, identifying ethical dilemmas, and demonstrating professional judgment in resolving dilemmas that arise (Austin et al. 2003).

Therefore, simulation-based learning activities like the OSCE's should also play an important role in the development of ethical clinicians by (1) addressing the moral components of ethical decision making and (2) facilitating the learning process to enhance clinical and ethical competence.

\section{Addressing the Moral Components of Ethical Decision Making}

Ethical decision making has widely been considered an exercise in moral decision making (Murphy and Hecker 2016; Wilcoxon et al. 2012). In fact, Knapp and VandeCreek (2003) describe ethical codes of professional organizations as incomplete moral codes. The outcome of these 
ethical decisions is strongly influenced by the clinicians' beliefs, values, worldviews and the specific context of the dilemma at hand (Murphy and Hecker 2016; Wilcoxon et al. 2012). Unfortunately, therapists in training often lack the self-awareness and experience necessary to understand that values need not be static entities that denote a right or wrong way of doing things. Rather, valuing is an evolving epistemological process (Wilcoxon et al. 2012) in which values unfold within the context of the dilemma and can often change dependent on the situation and context.

Researchers have expressed concern that the foundation of ethical decision making occurs subconsciously and automatically before it reaches the conscious part of the brain (Drumwright et al. 2015). This often results in clinicians inadvertently bypassing the necessary steps of selfreflection, because their brain is looking for "cognitive shortcuts" (McMahon and Good 2016, p. 357) to simplify their ethical decision-making process. Therefore, it is critical that students in training programs intentionally examine their values, so they can acknowledge their biases, long before they face ethical dilemmas in practice (Oramas 2017). Even then, it is unclear if cognitive exercises are adequate to prepare students for actual practice. The concern being they are experienced in a context devoid of the type of interactions embedded in real-life ethical encounters. Feminists have long extolled the potential unintentional harm involved for clients when clinicians are unaware of their personal biases related to their work (Hare-Mustin 1978). Consequently, exercises such as value clarifications (Wilcoxon et al. 2012) have been the primary way of helping students acknowledge the presence and impact of their personal values. Similarly, to the application of ethical decision-making models, students are presented with basic beliefs or positions and asked to work through a series of steps. The goal is to assist students in consciously choosing, prizing and acting on certain beliefs. The hope is encouraging students to understand the impact of their personal values on their decision-making process will result in clinical actions that more concretely focus on the client's values and best interest (Wilcoxon et al. 2012).

Unfortunately, reasoning in an ethical way is never as easy in practice given that therapy is an unpredictable mix of intuition and rationality (Woody 1990), and is often fraught with emotional reactivity. Consequently, determining a course of professional behavior that not only avoids ethical misconduct, but prepares clinicians in how to deal with their own personal reactivity is critical. To achieve this, these activities 
must extend beyond a cognitive exercise. Training must include helping clinicians acknowledge personal experiences that influence their moral decision making. This is critical because ethics is concerned with behavior, while one's values relate to beliefs and attitudes that determine how individuals behave (Oramas 2017). It is therefore important for clinicians in training to begin the process of integrating their personal and professional identities, so their own knowledge, integrity and judgment can be scrutinized as a factor in the process of arriving at an ethical decision (Oramas 2017; Woody 1990). Simulation-based learning activities or OSCE's are incredibly important, because they push students to experience the complexities of reasoning in an ethical way in a real time situation.

\section{Facilitating the Learning Process}

Simulation-based learning activities are based on the idea that adults learn best when they are actively engaged with the material in experiential ways, including role plays based on real life experiences. This learning is further enhanced when students experience concrete events in both a cognitive and emotional fashion. (Fanning and Gaba 2007). Students must be given the opportunity to engage and demonstrate their understanding of ethical decision making while protecting clients from unnecessary risks. Research conducted on OSCEs shows students generally perform better the second time they complete the exam. Researchers reason the opportunity to reflect on how they used their skills and what they could have done different explains this increased performance (Alinier 2003). This process of learning mirrors recommendations made in ethical decision-making literature that clinician's evaluate choices they made in resolving dilemmas and consider what they would do different the next time (Murphy and Hecker 2016; Wilcoxon et al. 2012). This simulated learning environment allows learning and re-learning before real clinical stakes are involved. These activities also allow classroom material to come alive, while enhancing efficiency of the learning process in a controlled environment (Gaba et al. 1998; Lateef 2010).

Experiential learning activities are highly beneficial because they highlight both student's skills and deficits (Miller 1990) in how they manage their own emotional reactivity, set appropriate boundaries and implement plans that do the least amount of harm and promote the most 
good. This provides a safe environment for students to fail and receive helpful feedback from supervisors and peers. Research has also demonstrated that experiential learning opportunities help students develop attitudes like resilience, tenacity, self-awareness and self-confidence in their ability to complete a task (Alinier 2003). These attitudes form the foundation for sound ethical clinical practice.

Ethics in Action was created in response to the need to give students an opportunity to apply an ethical decision-making model in a manner that engaged not only their cognitive and reasoning abilities, but their emotional experiences, personal values and beliefs. The goal was to provide a context that mirrored the actual stresses and time pressures involved with encountering an ethical dilemma in practice. While this context is obviously present in practicum and internship experiences, clinical training in the field of Couple and Family Therapy is often missing an intermediate stage where students can apply skills in a realistic setting, while also protecting clients by assuring student therapists have the skills necessary before engaging in face-to-face contact (Miller 2010). This setting allows students to experience aspects of ethical decision making that do not materialize in a written case scenario (e.g., the emotional underpinnings of the relationship). Ultimately, Ethics in Action helps students deal with their own anxiety, values and beliefs in real time, as well as demonstrating their learning beyond an academic written assignment.

\section{The Intervention-Ethics in Action}

Ethics in Action is an OSCE based activity developed for use in an ethics course situated near the beginning of clinical training. The activity itself is a series of case scenarios that have been scripted. Students are assigned a role and together they engage in a therapy session (50 min-1 $\mathrm{h}$ per scenario) that builds toward an ethical dilemma. Afterward, the students process the experience as a group (30-40 $\mathrm{min}$ ) and complete a follow up paper that allows them to further expand upon and concretize what they have learned. None of the students are aware ahead of time what dilemma will emerge during their "therapy session" since they are only given information regarding the overall context of the clients and the specific role they will be playing. This description includes prompts 
about how they may be feeling and information they need to introduce into the therapy session. It is a combination of students' contributions to the role play that create the ethical dilemma. Those given a professional role (e.g., therapist or supervisor) are then tasked with addressing the dilemma that has arisen.

In contrast to traditional OSCE protocol which utilizes trained actors to play the part of clients or patients, students assume these roles in addition to the roles of the professional. This modification was made in order to challenge students to consider ethical dilemmas from the perspective of different stakeholders in the therapy; most particularly allowing them to experience the dilemma and impact of decisions as a client might. It has been noted that students may have a more difficult time engaging in role-plays in a serious manner when interacting with their peers (Pomerantz 2003). However, based on the current authors experiences, the length of the activity really allows students to move beyond initial stages of levity in order to fully engage with the material. In reflecting on the assignment, the majority of students reported they forgot they were acting and began to experience the scenario at an emotional level as though it were happening to them. This allowed trainees to more deeply consider the consequences of even seemingly small decisions made in the therapy room on the lives and feelings of their future clients.

\section{Scenario Development}

Hodges et al.'s (2002) recommendations, were utilized in developing the scenarios. First, all material was derived from actual clinical cases and situations. These experiences were collected from the first author's personal clinical experiences and those of colleagues. This step ensures a connection with actual practice and helps to guard against the development of unrealistic or overly simplistic scenarios. All scenarios have been edited and changes have been made that balance the need to remain consistent with the most salient points that created the dilemma while protecting the identities of individuals involved. In addition, when processing the activity students often wonder about how the actual therapist addressed the dilemma and the outcome of the case. Being privy to these details provides the opportunity for rich discussion and for 
students to really grasp the multiple ways in which ethical dilemmas can be addressed. Additionally, they are able to consider how their process may have differed from another clinician's.

Next, core aspects of ethical decision making were identified through a search of the literature and based on the core competencies outlined by the Commission on Accreditation of Marriage and Family Therapy Education (COAMFTE). For example, one scenario aligns with the following core competencies: 2.3.5 "Screen and develop adequate safety plans for substance abuse, child and elder maltreatment, domestic violence, physical violence, suicide potential, and dangerousness to self and others" (Nelson et al. 2007, p. 434); 3.4 .3 "Evaluate level of risks, management of risks, crises, and emergencies" (Nelson et al. 2007, p. 435); and 5.3.4 "Develop safety plans for clients who present with potential selfharm, suicide, abuse, or violence" (Nelson et al. 2007, p. 437).

Third, common ethical dilemmas in the field of Couple and Family Therapy (e.g., confidentiality, duty to warn) and current issues facing the field (e.g., delivering culturally sensitive and competent treatment for LGBTQQ clients) were identified through literature searches and reviews of clinical topics presented at AAMFT, AFTA, and IFTA. Search criteria included texts and journal articles specific to ethical practice in MFT and a five-year review of articles pertaining to clinical practice in select journals. Journals were selected for their focus on clinical practice in systems-focused therapies. In order to meet criteria for inclusion, scenarios had to represent issues present in one or both areas (core ethical dilemmas and current issues).

\section{Description of Scenarios}

Each scenario consists of (1) a description of the client group, the therapist, and background details a therapist would know if working with the family, and (2) specific details to be provided only to the individual assigned to that role. Each scenario comprises four main roles, including: the clients, the therapist, the supervision or consulting team, and the supervisor. In larger groups, a shadow therapist (observer) can also be used. The shadow therapist observes quietly and makes notes on how they would proceed as the therapist in the case, but does not directly intervene in the session. Scenarios are also structured to provide 
students experience with different contextual factors that will influence their work as therapists and supervisors (e.g., the availability of live supervision versus only case report supervision) and steps they will need to take in enacting their ethical decision-making model.

\section{Protocol}

The following describes the protocol for running the Ethics in Action exercise. It is best implemented near the end of the course, once students have been exposed to the concept of ethical decision making, the American Association for Marriage and Family Therapy code of ethics, ethical principles, the impact of personal values on decision-making, specific ethical minefields in the practice of systemic therapy (e.g., ethical practice with oppressed communities) and legal statutes guiding their work. There are four main stages to enacting the protocol and ideally the exercise can be conducted over the course of one class session.

\section{Stage One: Preparing for the Role Plays}

Prior to implementing Ethics in Action, the instructor will want to consider a space to hold the activity. The more closely the space resembles the actual context a clinician finds themselves in, the more benefit students will gain from participating (Alinier 2003). Therefore, use of a University clinic, when available, is encouraged. If this is not a possibility, locating a space that has at least two rooms large enough to accommodate the class allows members to move in and out of the session as necessitated by the scenarios. There will be times when specific individuals should not have access to what is going on in the therapy session and would therefore need a different place to be. However, these rooms should be close enough to facilitate movement in and out of them within a short time span, such as when a client is asked to sit in the waiting room for a couple of minutes.

One week before implementing the activity, provide students with some background information on the cases that will be used during their exercise. These background details do not include information specific to the ethical dilemma, but rather give a broader description of the client groups the therapist is working with and some general ideas about 
the therapeutic relationship. While this step was not part of the initial activity, it was added after students reported they did not have the opportunity to really understand the case before beginning the session and therefore found themselves needing to collect a lot of general information at the beginning of the "session," which allowed less time to focus on and address the ethical dilemma when it arose. The additional information has enabled students to enter the therapy room with a level of preparedness expected out of a clinician who would interacted with the family previously, thereby increasing the realistic nature of the encounter.

\section{Stage Two: Engaging in the Role Plays}

Students should be divided into groups consisting of six to eight individuals in order to assure each person is assigned a role (e.g., specific client role, therapist, supervisor, etc.) and to keep groups small enough to encourage higher quality processing in later stages of the activity. Once groups have been formed, assign members to a role and distribute additional information specific to their role and the scenario they will be acting out. Instruct students not to share their roles with one another. The directions provided in the role scripts allow an ethical dilemma to emerge without the therapist, family members, or supervisor anticipating the dilemma ahead of time, thus mirroring real life.

Participants are also instructed how to access their supervisor or additional resources given their context (e.g., they work in a setting where their supervisor is available by phone or their supervisor is behind the mirror). Once all members are prepared, groups are given $60 \mathrm{~min}$ to engage in the scenario, allowing them time for a standard clinical hour plus additional time for supervision or consultation as needed. In addition, the time frame allows students to get into their role and maximizes the impact of the activity on learning. Students gain valuable experience regardless of whether they are assigned a professional or personal role. However, feedback from students over 7 years of implementing this exercise demonstrates that what they learn is slightly different. For example, students placed in the role of therapist discuss the immense pressure they feel to make sound decisions sometimes with very little time. In contrast, students who take the role of clients focus a lot of attention on the impact of decisions made in therapy on their feelings about the therapist and their sense of trust in the process. Given this feedback, the 
ideal situation is to allow each student to be involved in two scenarios, one serving in a professional role (e.g., therapist, supervisor, observer) and the other in a client role.

\section{Stage Three: Debriefing the Role Plays}

Debriefing is the cornerstone of experiential learning (Fanning and Gaba 2007). The process of debriefing represents guided reflection on the individual and group's experiences with the experiential activity. This reflective process is considered an important part of ethical decision making as it pushes practitioners to learn from their experiences. A two-stage approach to de-briefing the Ethics in Action experience was developed in order to take advantage of the impact of time on how persons process their experience (Lederman 1991).

The first step of debriefing takes places immediately following the activity. In this step, a facilitator should guide students to process how they experienced the activity from their particular vantage point (e.g., therapist, client, etc.). Debriefing at this point should focus on the trainees own personal reactions and feelings about their participation, the decision-making process, and the impact of decisions made on stakeholders involved. Encouraging students to evaluate the decisions made throughout this process is not usually helpful at this point, as most students need more time and space to consider their experience from a distance.

This step of the reflecting protocol is particularly important in helping students to focus on the impact of their decisions on individuals involved in therapy. At this point, students who were in the role of professionals are able to hear from students who served as clients about how their interventions were received. Most ethical decision-making models ask therapists to consider the possible and probable impact of their decisions on clients (Cottone and Claus 2000; Murphy and Hecker 2016) This stage of the activity creates a rich discussion that pushes students to consider these outcomes in a deeper and more meaningful way. For example, in one session a therapist asked one member of a couple to sit in the waiting room while he processed an issue with her partner. The client was left in the waiting room for $30 \mathrm{~min}$ without any insight regarding what the therapist and her partner were discussing in the room. During the debriefing, the student who portrayed 
the client left in the waiting room was able to share the hurt and anger she felt, how the experience damaged the therapeutic relationship, and the likely outcome (that she would not return to therapy). All members of her group were moved by her experience and proceeded to reflect on it and how it would shape decisions they made in the future when working with clients.

Debriefing at this point also assists the students in getting out of character. As exemplified above, students can become quite immersed in the activity and experience strong emotional reactions toward one another, based on their interactions during the "therapy session." Although deception is not involved in the process, debriefing may be necessary to alleviate any negative effects the experience may have produced in students (Fanning and Gaba 2007). For example, after one scenario in which two supervisors argued about what they believed was the best course of action, they were able to focus on the origin of their values in the debriefing session. This led to a consideration by both regarding the ways in which their personal experiences may have gotten in the way working together effectively to do what was best for clients. It also allowed them to address residual frustration felt toward one another as a result of not being heard during the activity. It was a very emotional experience for all involved, including students who served in observing roles in the class.

\section{Stage Four: Write a Reflection/Evaluation Paper on the Experience}

The second step of the de-briefing process is accomplished by giving the student's a period of time after the experience to reflect more on the role play and to evaluate their own process. The ability to evaluate clinical decisions and learn from them is a seminal part of ethical decision making (Kitchner 1984). This allows practitioners to learn from successes and mistakes while honing clinical experiences for the benefit of current and future clients. During the final step, students are asked to reflect on their experiences from more of a distance, generally 1-2 weeks, and to begin the process of evaluating decisions made, including their rationale for those decisions and the process they engaged in to make decisions. 


\section{Future Directions}

It is our duty as educators of the next generation of MFT's to empower students to learn and understand ethical decision making in new ways. The first step in doing this, is to move beyond the traditional cognitive exercises of ethical decision making and allow students to immerse themselves in the complexities of ethical decision making well before they are faced with meeting with their first client. To date, Ethics in Action has been used for seven years, as described, in a minimum of four different programs. Information related to its effectiveness has been gathered in the feedback from students at the completion of courses and alumni who continue to comment on its effectiveness in preparing them for the next stage of their development; practice with actual clients. The next step will be to explore the outcomes of this teaching method in a more formalized manner. Given that OSCE's have been used in medical training both in a formative manner, as described above, and as a summative evaluation, there may be value to developing a more formalized evaluation rubric to give students' feedback on their implementation of ethical decision-making skills during the activity. Another area for exploration is the impact of engagement in Ethics in Action on trainees' ethical performance during their entry clinical training experiences. Finally, given feedback from students and alumni over the years, it would be important to understand at a deeper level what students find transformative about engaging in this experience and how it impacted their ethical decision making moving forward.

Conflicts of interest Dr. Bobbi Miller currently serves on the Editorial Board of Contemporary Family Therapy Journal. Dr. Paul Springer has no conflicts to report.

\section{Appendix 1: Example Scenario and Scripts}

\section{Scenario}

The scenario deals with a divorcing couple who share custody of one child and have been seeking therapy. The initial goal was to work on the relationship and has since shifted to adjusting to the reality of the divorce and the 
impact on the child. This scenario involves child abuse in the context of a contentious divorce.

\section{Scripts}

\section{Therapist}

You have been working with a family for about one year; Partner 1 (39), Partner 2 (38), and Child (11). The initial goal was to save the relationship/ marriage, but the couple decided to separate/divorce during therapy. The family has remained in family therapy with you. The goal has changed to managing the transition to their new status as a divorced family effectively. You have been seeing the family together and seeing the child some individually as well. The divorce process has been very contentious. You are attempting to work with them on how to co-parent throughout this transition, but you have begun to notice that their interactions are getting more and more hostile. You have also noticed that you are beginning to feel more frustrated and reactive toward partner 2. You believe that many of their demands on their partner and child are unreasonable. One afternoon between sessions you receive a phone call from partner 1. They tell you that they are concerned about something that they found out and does not know what to do. They report to you that their child came back from staying with partner 2 and is refusing to go back. Partner 1 tells you that the child won't tell them what happened, but seems to "indicate" that partner 2 hurt them somehow. Partner 1 says that they are very concerned and does not want to 'make" their child go to the house of partner 2 again.

\section{Partner 1}

You have been seeing a therapist for about one year. First the goal was to try and save your marriage/relationship. However, you and your partner have decided to get divorced. You have continued to engage in therapy in an attempt to work on co-parenting your child even after the separation/divorce. You believe that your partner is being uncooperative with the plan and you recently found out that they have been dating someone. You are very angry about this and have been venting to friends, sometimes around your child. A couple of nights ago, your child came home from your partner's house very upset. Your child refused to tell you what happened, but reported to you that they would not go to your partner's house again. You have seen your ex-partner get very angry and lose their temper and you are concerned about what they might have done. You call your therapist to report your concerns that your partner may have abused your child. 


\section{Partner 2}

You have been seeing a therapist for about one year. First the goal was to try and save your marriage/relationship. However, you and your partner have decided to get divorced. You have continued to engage in therapy in an attempt to work on co-parenting your child even after the separation/ divorce. You believe that your partner is talking behind your back to your child and have noticed more and more of an attitude from your child when they stay with you. You find yourself getting really frustrated your child. The last time they visited, you got very angry, grabbed them by the hair and slapped them across the face. You are appalled that you did this and apologized profusely, but your child refused to talk to you for the rest of the trip. You have never done anything like this before. You do not say anything to anyone about what happened. You are very concerned about what this might mean for your ability to keep your child.

\section{Child (11)}

You have been seeing a therapist for about six months. First the goal was to try and save your parents' marriage/relationship. However, they have decided to get divorced. Now therapy sometimes involves you. Sometimes you speak with the therapist with your parents and sometime you talk to the therapist alone. You are feeling very torn between your parents. Parent 1 is very angry with parent 2 and always talking about what an awful person they are and how it is their fault the two got divorced. Parent 2 has also started to date someone and this makes you angry. You have been sulking more and giving parent 2 more attitude. Parent 2 has been more frustrated with you. At your last visit, you and parent 2 got into a fight and they grabbed you by the hair and slapped you across the face. You are very angry with parent 2 and do not want to go to their house again. You go home and tell your parent 1 that you do not want to return to parent 2's house. However, you love parent 2 and don't want them to get into trouble, so you don't tell parent 1 what happened. Parent 1 has been so angry at parent 2 , you are not sure what they would do if you did tell them. (If the therapist asks you what happened, go ahead and tell the therapist but insist that they do not tell anyone including your parents).

\section{Supervisor}

Your supervisee has encountered a dilemma that they are going to come and talk to you about. Your team and the supervisee have been working together for about 6 months. You have noticed that the therapist seems especially bonded with the child and at times has a difficult time connecting with parent 2. (You will need to provide some feedback to your supervisee about how 
to proceed with their dilemma; you can also provide suggestions about where your supervisee could go for more information. Feel ask your supervisee any questions that you need to).

Observer (Therapist)

Your role is to follow the therapist throughout the entire activity. Think about the choices that you would make in their role. Focus on what you would do similar and what you might do different. Also focus on why you might do some things similarly or in a different way? Do not intrude on the process. Your job is simply to observe. You will be sharing some of your observations at the end of the activity, so I would encourage to you to take notes.

\section{Appendix 2: Debriefing Guide-Step One}

As we debrief today, please describe your experiences to the extend you feel safe to do so. If you need extra time to debrief anything sensitive that you are not able to share with the group, please let me know and we can meet privately.

1. Describe the experience of being part of this therapy session. What feelings came up for you?

2. Were there experiences that were particularly triggering for you? If so, what were they and what make them difficult.

3. What was your role in the activity and how did your role shape your perspective of the decisions made in therapy?

4. For those with a professional role:

a. Was there anything specific to the context that made it hard for you to do your job? If so, what?

b. Would you have changed anything that happened? If so, what and why?

c. Did you find yourself stuck at any point about how to proceed? If so, at what point and why?

5. For the clients:

a. How did you feel about your relationship with the therapist throughout the session? At the end of the session?

b. Would you come back to therapy? Why or why not?

c. What made you feel cared for in this interaction? How could you have experienced more care? 


\section{Appendix 3: De-Briefing Guide Stage Two: Reflection/Evaluation Paper Directions and Grading Rubric}

Overview: This paper should describe your experience as the therapist, supervisor, consultant, or observer during the role play. You are expected to demonstrate your ability to identify, seek out additional information, and make a decision about the ethical dilemma that you are presented with. This decision should reflect an understanding of the stakeholders involved and their perspectives, as well as the complexity of the issues involved.

Your paper should discuss the following issues: (1) what was your role in the activity and how did your role shape your perspective of the decision made; (2) if you were the therapist, identify the ethical dilemma and the decision that you ultimately made; if you were the supervisor/consultant, identify the ethical dilemma and the guidance that you provided to your supervisee/colleague; if you were an observer, identify the ethical dilemma, the decision that the therapist made and whether you would have made the same decision (3) using the ethical principles AND codes support the decision that you made, guidance that you gave, or decision you would have made, (4) identify the key stakeholders in this scenario and the process that you took (or would have taken) to consider their needs in making your decision, (5) briefly review the process that you took to make your decision and anything that you would have changed about your process after receiving feedback from the individuals involved.

Your paper should be between three to five pages. It will be graded on its clarity and how well you address the issues described above. In addition, organization, quality of writing (sentences are well formed, varied in length and style, effective use of paragraphs), Use of APA style: professionalism (12 pt font, Times and roman, 1-inch margins), mechanics (free of spelling, typographical and grammatical errors), and use of headings.

Values Paper Grading Rubric.

- Attended session on time and fully participated in activity/85

- Clearly identified own role and influence of the role on decision making process $/ 7$

- Clearly and correctly identified ethical dilemma(s) present/8

- Supported decision using both ethical codes AND Principles; use of codes and principles demonstrated familiarity with both/20

- Identified key stakeholders in scenario and reflected on how they were included in the decision-making process /15

- Clearly articulated process of making the decision and any changes s/ he would make next time/15

150 Points: Points will be taken off for any problems with organization, quality of writing and use of APA (American Psychological Association Publication Manual). 


\section{References}

Alinier, G. (2003). Nursing students' and lecturers' perspectives of objective structured clinical examination incorporating simulation. Nurse Education Today, 23(6), 419-426. https://doi. org/10.1016/S0260-6917(03)00044-3.

Austin, Z., O'Byrne, C., Pugsley, J., \& Munoz, L. (2003). Development and validation processes of an objective structured clinical examination (OSCE) for entry-topractice certification in pharmacy: The Canadian experience. American Journal of Pharmacy Education. https://doi.org/10.5688/aj670376.

Bush, S. S., Connell, M. A., \& Denney, R. L. (2006). Ethical practice in forensic psychology: A systematic model for decision making. American Psychological Association. https://doi. org/10.1037/11469-000.

Caldwell, B. E., \& Stone, D. J. (2016). Using scaling to facilitate ethical decisionmaking in family therapy. American Journal of Family Therapy, 44(4), 198-210. https://doi.org/10.1080/01926187.2016.1150797.

Corey, G., Corey, M. S., \& Callanan, P. (2014). Issues and ethics in the helping professions with 2014 ACA Codes (9th ed.). Delhi: Brooks/Cole.

Cottone, R. R., \& Claus, R. E. (2000). Ethical decision-making models: A review of the literature. Journal of Counseling \& Development, 79(3), 275-283. https://doi. org/10.1002/j.1556-6676.2000.tb01908.x.

Cottone, R. R., Tarvydas, V. M., \& Claus, R. E. (2007). Ethical decision-making processes. In R. R. Cottone \& V. M. Tarvydas (Eds.), Counseling ethics and decision making (pp. 85-113). Pearson/ Merrill Prentice Hall.

Coy, J. S., Lambert, J. E., \& Miller, M. M. (2016). Stories of the accused: A phenomenological inquiry of MFTS and accusations of unprofessional conduct. Journal of Marital and Family Therapy, 42(1), 139-152. https://doi.org/10.1111/ jmft.12109.

Drumwright, M., Prentice, R., \& Biasucci, C. (2015). Behavioral ethics and teaching ethical decision making. Decision Sciences Journal of Innovative Education, 13(3), 431-438. https://doi.org/10.1111/ dsji.12071.

Edinger, W., Robertson, J., Skeel, J., \& Schoonmaker, J. (1999). Using standardized patients to teach clinical ethics. Medical Education On-Line. https://doi. org/10.3402/meo.v4i.4306.

Fanning, R., \& Gaba, D. (2007). The role of debriefing in simulation-based learning. Society in Simulation in Healthcare, 2(2), 115-125. https://doi.org/10.1097/ $\underline{\text { SIH.0b013e3180315539. }}$

Forester-Miller, H., \& Davis, T. E. (1996). A practitioner's guide to ethical decision making. Alexandria, VA: American Counseling Association.

Foster, D., \& Black, T. G. (2007). An integral approach to counseling ethics. Counseling and Values, 51(3), 221-234. https://doi. org/10.1002/j.2161-007X.2007. tb00080.x.

Gaba, D. M., Howard, S. K., Flanagan, B., Smith, B. E., Fish, K. J., \& Botney, R. (1998). Assessment of clinical performance during simulated crises using both technical 
and behavioral ratings. Anesthesiology, 89(1), 8-18.

Green, S. L., \& Hansen, J. C. (1989). Ethical Dilemmas faced by family therapists. Journal of Marital and Family Therapy, 15(2), 149-158. https://doi. org/10.1111/j.1752-0606.1989.tb00794.x.

Handelsman, M. M., Knapp, S., \& Gottlieb, M. C. (2002). Positive ethics. In C. R. Snyder \& S. J. Lopez (Eds.), Handbook of positive psychology (pp. 731-744). Oxford: Oxford University Press.

Hare-Mustin, R. T. (1978). A feminist approach to family therapy. Family Process, 17(2), 181-194. https://doi.org/10.111 1/j.1545-5300.1978.00181.x.

Hicks, M. W., \& Cornile, T. A. (1999). Gender, power, and relationship ethics in family therapy education. Contemporary Family Therapy, 21(1), 45-56. https://doi. org/10.1023/A:1021910620587.

Hodges, B., Hanson, M., McNaughton, N., \& Regehr, G. (2002). Creating, monitoring, and improving a psychiatry OSCE: A guide for faculty. Academic Psychiatry, 26(3), 134-161. https://doi. org/10.1176/appi.ap.26.3.134.

Inman, A. G., Hutman, H., Pendse, A., Devdas, L., \& Luu, L., \& Ellis, M. V., (2014). Current trends concerning supervisors, supervisees, and clients in clinical supervision. In C. E. Watkins \& D. L. Milne (Eds.), The Wiley international handbook of clinical supervision (pp. 61-102). Hoboken: Wiley.

Jankowski, P. J., \& Martin, M. J. (2003). Reporting cases of child maltreatment: Decision-making processes of family therapists in Illinois. Contemporary Family Therapy, 25(3), 311-332. https:// doi.org/10.1023/A:1024511405704.

Kitchener, K. S. (1984). Intuition, critical evaluation and ethical principles: The foundation for ethical decision in counseling psychology. The Counseling Psychologist, 12(3), 43-55. https://doi. org/10.1177/0011000084123005.

Knapp, S., \& VandeCreek, L. (2003). An overview of the major changes in the 2002 APA Ethics Code. Professional Psychology: Research and Practice, 34(3), 301-308. https://doi. org/10.1037/0735-7028.34.3.301.

Koocher, G. P., \& Keith-Spiegel, P. (2008). Ethics in psychology and the mental health professions: Standards and cases (3rd ed.). Oxford: Oxford University Press.

Lateef, F. (2010). Simulation-based learning: Just like the real thing. Journal of Emergencies Trauma and Shock, 3(4), 348-352. https://doi. org/10.4103/0974-2700.70743.

Levitt, D. H., Farry, T. J., \& Mazzarella, J. R. (2015). Counselor ethical reasoning: Decision-making practice versus theory. Counseling and Values, 60(1), 84-99. https://doi.org/10.1002/j.2161-007X.2015.00062.X.

Lederman, L. C. (1991). Differences that make a difference: Intercultural communication, simulation, and the debriefing process in diverse interaction. Annual Conference of the International Simulation and Gaming Association. Address conducted at the meeting of the International Simulation and Gaming Association, Kyoto.

McMahon, J. M., \& Good, D. J. (2016). The moral metacognition scale: Development and validation. Ethics \& Behavior, 26(5), 357-394. https://doi.org/10.1080/1050 
8422.2015.1028548.

Mead, D. E. (1990). Effective supervision: A task-oriented model for the mental health professions. London: Brunner/Mazel.

Melito, R. (2003). Values in the role of the family therapist: Self-determination and justice. Journal of Marital and Family Therapy, 29(1), 3-11. https://doi. org/10.1111/j.1752-0606.2003.tb00378.x. Milne, D. K. (2014). Toward an evidence-based approach to clinical supervision. In C. E. Watkins \& D. L. Milne (Eds.), The Wiley international handbook of clinical supervision (pp. 38-60). Hoboken: Wiley.

McLaurin, S. L., Ricci, R. J., \& McWey, L. M. (2004). A developmental perspective of marriage and family therapist's ethical principles: Support for the practitionerethics relationship model. Contemporary Family Therapy, 26(3), 293-306. https:// doi. org/10.1023/B:COFT.0000037916.88984.b1.

McLaurin, S. L., \& Ricci, R. J. (2003). Ethical issues and at-risk behaviors in marriage and family therapy: A qualitative study of awareness. Contemporary Family Therapy, 25(4), 453-466. https://doi. org/10.1023/A:1027364804008.

Miller, G. E. (1990). The assessment of clinical skills/competence/ performance. Academic Medicine, 65(9), S63-S67. https://doi. org/10.1097/00001888-199009000-00045.

Miller, J. K. (2010). Competency-based training: Objective Structured Clinical Exercises (OSCE) in marriage and family therapy. Journal of Marital and Family Therapy, 36(3), 320-332. https://doi. org/10.1111/j.1752-0606.2009.00143.x.

Morgan, M. M., \& Sprenkle, D. H. (2007). Toward a common-factors approach to supervision. Journal of Marital and Family Therapy, 33(1), 1-17. https://doi. org/10.1111/j.1752-0606.2007.00001.x.

Murphy, M. J., \& Hecker, L. (2016). Ethics and professional issues in couple and family therapy. Routledge: Taylor \& Francis.

Nelson, T. S., Chenail, R. J., Alexander, J. F., Crane, D. R., Johnson, S. M., \& Schwallie, L. (2007). The development of core competencies for the practice of marriage and family therapy. Journal of Marital and Family Therapy, 33(4), 417-438. https:// doi.org/10. 1111/j.1752-0606.2007.00042.x.

Oramas, J. E. (2017). Counseling ethics: Overview of challenges, responsibilities and recommended practices. Journal of Multidisciplinary Research, 9(3), 47-58.

Pomerantz, A. M. (2003). Who plays the client? Collaborating with theater departments to enhance clinical psychology role-play training exercises. Journal of Clinical psychology, 59(3), 363- 368. https://doi.org/10.1002/jclp.10079.

Tarvydas, V. M., Vazquez Ramos, R. A., \& Estrada-Hernandez, N. (2015). Applied participatory ethics: Bridging the social justice chasm between counselor and client. Counseling and Values, 60(2), 218-233. https://doi.org/10.1002/ cvj.12015.

Taylor, R., \& Gonzales, F. (2005). Communication flow and change theory within a family therapy supervision model. Contemporary Family Therapy, 27, 163-176. 
https://doi.org/10.1007/s10591-005-4037-3.

Thomas, F. (2008). Being good, doing good: The virtue of goodness in ethical practice. A plenary presented for the Annual Conference of the American Association for Marriage and Family Therapy, Memphis, TN, November 1, 2008.

Todd, T. C., \& Storm, C. L. (1997). The complete systemic supervisor: Context, philosophies, and pragmatics. Routledge: Allyn \& Bacon.

Wilcoxon, S. A., Remley, T. P., \& Gladding, S. T. (2012). Ethical, legal, and professional issues in the practice of marriage and family therapy (5th ed.). London: Pearson.

Woody, J. D. (1990). Resolving ethical concerns in clinical practice: Toward a pragmatic model. Journal of Marital and Family Therapy 16(2), 133-150. https:// doi.org/10.1111/j.1752-0606.1990.0834.x. 